\title{
REVIEWS
}

\section{Most Recent Evidence Behind Aggregometry and Genotyping Methods as Platelet Function Testing for Tailored Anti-Platelet Treatment Among PCI Patients}

$1^{\text {st }}$ Department of Cardiology, Public Central Teaching Hospital, Warszawa, Poland

A - research concept and design; $\mathbf{B}$ - collection and/or assembly of data; $\mathbf{C}$ - data analysis and interpretation;

$\mathbf{D}$ - writing the article; $\mathbf{E}$ - critical revision of the article; $\mathbf{F}$ - final approval of article; $\mathbf{G}$ - other

\begin{abstract}
Aggregometry and genotyping are methods of platelet function testing, which can be beneficial for high-risk patients undergoing invasive cardiac procedures. An optimal level of platelet reactivity (PR) should be maintained. There are discrepancies between individuals and their response to clopidogrel, accounting for the incidence of poor responders from $5 \%$ to $44 \%$. This phenomenon predisposes the patients to increased risk of ischaemic events and thereby overall poorer clinical outcome. Prasugrel and tricagrelor are newer without genetic correlation to their action, however associated with increased bleeding risk. Aggregometry methods assess platelet reactivity at the exact moment of blood sampling. They reflect "phenotype" of the patient and vary after drug administration or dose change. The most popular tests are Light Transmission Aggregometry, Vasodilator-Stimulated Protein, VerifyNow, Multiple Electrode Aggregometry and Thrombelastography. There is proven genetic correlation between some cytochrome enzymes on clopidogrel response. The most widely tested is gene CYP2C19, which produces the enzyme transforming clopidogrel into an active metabolite. The CYP2C19*2 allele carriers have higher PR which can result in more thrombotic events. The manuscript shows the most recent evidence behind platelet function testing. Aggregometry is shown to be beneficial in 5 trials and 1 meta-analysis, while one paper was of different opinion. Ten studies show a positive clinical effect of genotyping on patients' outcome, while one does not support it. The best method of identifying high-risk individuals could be both methods and personalisation of antiplatelet therapy may decrease adverse ischaemic outcomes (Adv Clin Exp Med 2015, 24, 4, 687-693).
\end{abstract}

Key words: clopidogrel, platelet reactivity, aggregometry, PCI.

Inhibition of platelet reactivity $(\mathrm{PR})$ is crucial in preventing ischemic events in patients undergoing procedures like percutaneous coronary intervention (PCI) or transcatheter aortic valve implantation (TAVI). An optimal level of PR should be maintained, as too low a PR predisposes patients to bleeding. Peri-procedural assessment of PR can be done with various tests. Many studies have shown that PR-adjusted treatment is beneficial for patients [1]. Several clinical, genetic, and cellular factors are responsible for the variability in platelet reactivity, for instance; alternative pathways of platelet activation, patients' noncompliance, or drug-drug interactions with different gene polymorphisms which account for $15 \%$ to $20 \%$ of the variation in pharmacodynamic response [1]. More and more interest is focused on genotyping to tailor medications before procedure.

The most common pattern of antiplatelet treatment is dual therapy comprised of aspirin and a P2Y12-adenosine diphosphate (P2Y12-ADP) receptor antagonist. The most widely used ADP receptor antagonist is clopidogrel which irreversibly modifies the structure of the platelet adenosine diphosphate (ADP) - receptor named P2Y12, directly inhibiting the binding of the ligand to the receptor and stopping ADP-dependent IIb/IIIa glycoprotein complex activation. Clopidogrel is a pro-drug that must be converted to an active metabolite by hepatic cytochrome $\mathrm{P} 450$ in a 2 -step process. Clopidogrel is first metabolized into 2-oxo-clopidogrel. This intermediate metabolite is then hydrolyzed, creating 
a highly unstable active metabolite, which irreversibly reacts, as a thiol reagent, with the G-proteincoupled P2Y12 receptor on platelets [2,3]. Different correlations between the alleles of the gene encoding the enzyme and the PR have been observed. High on clopidogrel PR, also called clopidogrel resistance, is a known phenomenon, however the clinical meaning still requires greater body of evidence. The incidence of poor responders ranges from $5 \%$ to $44 \%$ [4]. Clopidogrel is gradually being replaced by the newer antiplatelet agents prasugrel and ticagrelor. There are more potent, increase clinical outcome in acute coronary syndrome (ACS) and are recommended by the ESC guidelines [5].

Whether genetic screening is sufficient to tailor the treatment among PCI and TAVI patients is still unknown. There are many studies in invasive cardiology investigating individualised pharmacotherapy, but none that addresses the TAVI population.

\section{Aggregometry - Types of Tests and Basic Principles}

\section{Light Transmission Aggregometry}

Light Transmission Aggregometry (LTA) is the method used in diagnosing platelet disorders as well as in measuring platelet reactivity after administration of drugs such as clopidogrel or aspirin. The samples are either platelet-poor plasma or whole blood. Different types of agonists are used to activate platelet aggregation, one of which is ADP. In LTA, the sample is placed in a cuvette between the light source and photocell. Addition of the agonist results in aggregation of the platelets which then absorb less light, the increase in light transmittance is detected. Results can be expressed as platelet aggregation percentage or by shape changes in curves representing platelet reactivity. Aggregometers performing LTA are offered by several manufacturers.

\section{The Vasodilator-Stimulated Protein Description}

Activation of P2Y12 (a Gi-coupled receptor) inhibits adenyl cyclase, resulting in a decrease of platelet cyclicadenosine monophosphate (cAMP). This leads to a decreased level of phosphorylated VASP, which can be measured by flow cytometry [6]. Platelet reactivity index (PRI) mirrors platelet reactivity and is inversely correlated with clopidogrel administration. The platelet reactivity can be expressed as PRI\%, the normal values range from
69 to $100 \%$ which were tested among healthy volunteers [7]. This method is also suitable for assessing all anti-P2Y12 drug-induced platelet inhibition.

\section{VerifyNow Description}

The VerifyNow P2Y12 (VN-P2Y12) assay measures platelet aggregation to fibrinogen-coated beads by detecting light transmission over time. A blood sample with decreased platelet function has low light transmittance, whereas normal platelet function produces a high signal. Results from the device are reported as PRU (platelet reactivity unit) reflecting aggregation and also as $\%$ inhibition index showing platelet response [8]. With administration of a drug like clopidogrel, we aim for low PRU results and a high \% inhibition index which reflect a greater platelet aggregation inhibition by the drug. There is a cut-off value for stating high on-treatment platelet reactivity (HTPR), a PRU of $\geq 240$ was defined for clopidogrel. Drugs which can be tested with this method include aspirin, plavix, ticlid, effient, aggrenox, persantine, pletal/cilostazo, and non-steroidal anti-inflammatory drugs (NSAIDs) like ibuprofen, diclofenac, indocin, and feldene.

\section{Multiple Electrode Aggregometry}

Multiplate by Roche is a new semi-automated new device used for the assessment of both ischemic and bleeding complication as well as the detection of platelet disorders [9]. Multiplate is distinguished by best predictivity and standarization with a low volume of whole blood. The MEA uses impedance aggregometry method without the need for blood centrifugation. It can analyze 5 samples with great sensitivity at the same time, which results in 30 tests per hour. It is also equipped with dual-sensor which provides improved quality control for each sample. A small quantity of blood is placed in disposable cell with built sensor and stirring bar. Platelets are tested with heparin-induced environment and their aggregation increases the electrical resistance on sensors. The results are presented as aggregation units and area under the curve of arbitrary units. The upper quintile of MEA results was set as the cut-off for low clopidogrel response in trial performed by Dirk Sibbing and others and published in Journal of the American College of Cardiology [10].

\section{Thrombelastography Description}

Thrombelastography (TEG) is a quick, near patient test, which graphically illustrates the speed, strength and stability of clot formation. It also tests 
haemostatic function ex vivo, incorporating all components of coagulation. These features make this device superior to VerifyNow and the Multiple Platelet Function analyser. Moreover, short TEG does not require a clinical laboratory or extensive sample processing and gives results within $15 \mathrm{~min}$. However, it must be emphasized that it lacks evidence and standardization, but there is some data in the literature.

\section{Evidence for Aggregometry}

A study conducted by Varenhorst et al. compared the effectiveness of point-of-care (POC) devices assessing platelet $\mathrm{P} 2 \mathrm{Y} 12$ inhibition with current standard reference methods of treatment. It compared the measurement of platelet function by the VN-P2Y12 POC device with P2Y12 function estimated by the VASP and LTA assays in patients with stable coronary artery disease. The $\mathrm{VN}$ -P2Y12 device is easier to operate than the LTA and VASP techniques. It is a more convenient and accessible method used on a daily basis. However, a very high blockade of $\mathrm{P} 2 \mathrm{Y} 12$ receptor may not be reflected in VN-P2Y12, in contrast to more traditional methods. In addition, the results confirmed quicker inhibition of platelet activity was achieved with prasugrel in comparison with clopidogrel [8].

Another study determined the usefulness of VN-P2Y12 in assessing the antiplatelet effects of ticagrelor and clopidogrel. The PR was similar in LTA and VN-P2Y12 devices [11]. LTA remains a gold standard in assessing platelet activity. However, it has some limitations; it is time-consuming and requires a trained technician. The VN-P2Y12 assay is effective in identifying (HTPR), however it may slightly overestimate the pharmacodynamic difference between clopidogrel and tricagrelor. Observations also revealed that compared with clopidogrel, ticagrelor exhibited lower PR after the initial loading dose [11].

Sambu et al. conducted a trial concerning personalized antiplatelet therapy (APT) among patients with stent thrombosis (ST). The response to aspirin and clopidogrel was assessed with TEG. The results confirmed substantial hyporesponsiveness to APT in patients with ST, which may suggest an increased prothrombotic tendency in this group. An individually-tailored therapy may improve outcome in this group [12].

One randomized trial performed in France, compared peri-procedural platelet reactivity monitoring with standard prasugrel therapy in patients undergoing PCI. Peri-procedural PR inhibition is crucial, as most early stent thrombosis occur within the first days after the procedure. The PR was measured by the VASP index and the results revealed PR monitoring was superior to prasugrel therapy in reducing the rate of HTPR. In addition, this strategy lessened the number of patients predisposed to bleeds due to low PR. Patients in the clopidogrel loading dose-adjustment group were more frequently within the predefined biological window of $\mathrm{PR}$ ranges as opposed to those in the prasugrel group ( 83 vs. $33.8 \%, p<0.0001$ ). This trial confirms the superiority of platelet aggregation monitoring in administering medications [13].

A similar study was done by Price et al. who tested PR with a VN-P2Y12 in patients after PCI. The findings from 2796 patients showed that ontreatment reactivity with PRU lower than 208 carried a lower risk of the primary end point at 60 days (hazard ratio $(\mathrm{HR})=0.23 ; 95 \%$ confidence interval $(\mathrm{CI})=0.05-0.98 ; \mathrm{p}=0.047)$ and also at 6 months (adjusted hazard ratio $=0.54 ; 95 \%$ confidence interval $=0.28-1.04 ; \mathrm{p}=0.065)$. The results show the effectiveness of platelet function testing in patients undergoing PCI [14].

Due to controversial results of several randomized trials, Aradi et al. conducted a meta-analysis on the efficiency and safety of intensified antiplatelet therapy (repeated loading or elevated maintenance doses of clopidogrel, prasugrel or glycoprotein IIb/IIIa inhibitor) on the basis of platelet reactivity testing versus standard clopidogrel dosing in PCI-treated patients with HTPR. The results of 10 clinical trials revealed that intensified treatment considerably reduced cardiovascular mortality, stent thrombosis and myocardial infarction. However, no difference was apparent in terms of major bleeding events. Overall, the benefit of the intensified treatment was meaningful for patients at high risk of ST, while disappeared in low-risk individuals. The authors of the article also stated that the aggregometry approach is also more economical due to the high costs of administering new-generation ADP receptor antagonists [15].

Some authors, however, do not support PR adjusted treatment. One such study was the ARCTIC [16]. 2440 randomised patients undergoing PCI were tested. Among the monitored group, VerifyNowP2Y12 and aspirin point-of-care assays were done and those patients with HTPR were administered an additional dose of clopidogrel, prasugrel, or aspirin along with glycoprotein IIb/ /IIIa inhibitors during the procedure. Results demonstrated that $34.6 \%$ patients in the monitored group reached the primary end point in comparison to $31.1 \%$ in the conventionally-treated group $(\mathrm{HR}=1.13 ; 95 \% \mathrm{CI}=0.98-1.29 ; \mathrm{p}=0.10$. The main secondary end point, i.e. stent thrombosis or any urgent revascularization was noted among $4.9 \%$ of the patients in the monitored group and $4.6 \%$ in the control group ( $\mathrm{HR}=1.06 ; 95 \%$ 
$\mathrm{CI}=0.74-1.52 ; \mathrm{p}=0.77)$. What is more, there were no improvements in ischemic outcomes and safety of the drug adjusted group in comparison with the conventional group [16].

\section{Genotyping - The Influence of Gene Profile on Platelet Reactivity and Clinical Implications}

The enzyme encoded by the CYP2C19 gene is responsible for clopidogrels' transformation into an active metabolite. Eighty five percent of the pro-drug is transformed to an inactive metabolite by esterase, while the rest is changed into an active form by two, CYP-dependent, oxidative steps. In contrast, prasugrel is oxidized by CYP enzyme to its active metabolite in a single step, without an apparent dead-end inactive pathway, which may be the reason why responsiveness to it is independent of genotype as will be presented later [17]. The CYP2C19* 2 allele carriers have higher a PR, as PR inhibition by the drug is insufficient. It can result in a substantial number of thrombotic events [18]. Another mechanism which influences the effectiveness of clopidogrel is a drug-efflux intestinal transporter P-glycoprotein, which acts against several other drugs as well. There are some studies showing a genetic association between its function and the absorption of clopidogrel [19].

It is noteworthy that the carriers of CYP$2 \mathrm{C} 19^{*} 2$ allele represent approximately $30 \%$ of the Caucasian population and about 50\% in East Asians. Among carriers, 90\% are heterozygotes and $10 \%$ are homozygotes [18].

There is a number of studies regarding the value of genotyping. Below we recall the most relevant.

In one trial, 10 genes encoding proteins responsible for absorption, metabolism and pharmacodynamics of clopidogrel were assessed by real time Polymerase Chain Reaction (PCR) and restriction fragment length polymorphism (RFLP). The data confirmed that $\mathrm{CYP} 2 \mathrm{C} 19^{\star} 2$ genetic variation resulted in 4-fold poorer response to the drug. Moreover, CYP2C9 ${ }^{\star} 3$ was associated with an impaired effect of the drug. This was the first study that reported the correlation between this allele and a response to the medication [19].

Another meta-analysis of 23 studies assessed the correlation between the loss-of-function CYP$2 \mathrm{C} 19^{*} 2$ variant and ischemic outcomes. The results revealed that the carriers of the CYP2C19*2 allele had about a 35\% higher risk for major adverse cardiovascular events (MACE) compared to non-carriers [18]. This gene variant also correlated with increased mortality rates. A similar risk of ST was reported for reduced-function allele carriers and early drug cessation.

Jean-Sebastien Hulot et al. genotyped 28 healthy male volunteers. Among CYP2C19 2 carriers, clopidogrel did not change platelet aggregation measured with the agonist ADP, while among ${ }^{*} 1{ }^{\star} 1$ subjects there was only $48.9 \% \pm 14.9 \%$ aggregation in comparison to baseline ( $\mathrm{p}<0.001)$. Heterozygotes showed platelet aggregation of $71.8 \%$ $\pm 14.6 \%$ ( $\mathrm{p}=0.22$ vs. baseline and $\mathrm{p}<0.003$ vs. ${ }^{\star} 1 /{ }^{\star} 1$ subjects). VASP phosphorylation methods revealed similar results. Obtained data also suggested a correlation between the CYP2C19* 2 allele and a decrease in platelet response to the drug [6].

The trial to assess improvement in therapeutic outcomes by optimizing platelet inhibition with prasugrel - thrombolysis in myocardial infarction (TRITON-TIMI 38) also tested drug responses based on genetic polymorphisms. It compared healthy subjects with ACS patients. Among individuals treated with clopidogrel, CYP2C192* carriers had a one third reduction in exposure to the active metabolite, lowered platelet inhibition, and a higher occurrence of MACE, including ST compared to non-carriers [20].

The next study, which enrolled 2208 patients with acute myocardial infarction, also confirmed that the rate of cardiovascular events among patients with the CYP2C19 loss-of-function allele was 3.58 times higher than non-carriers (95\% $\mathrm{CI}=1.71-7.51)$. This fact was especially evident among PCI-treated individuals [21].

The ELEVATE-TIMI 56 trial published in 2011, examined genotype-tailored clopidogrel dosing and their effect on PR. Doctors tested whether maintenance doses of up to $300 \mathrm{mg}$ daily can elevate platelet reactivity in CYP2C19*2 carriers. Among patients with stable cardiovascular disease, increasing the dose of clopidogrel to $225 \mathrm{mg}$ daily in CYP2C19*2 heterozygotes resulted in a similar $\mathrm{PR}$ as the standard 75-mg dose in non-carriers; in contrast, homozygotes, even on a $300 \mathrm{mg}$ dose did not reach optimal platelet inhibition [22].

RAPID GENE trial compared for the first time the use of a novel rapid genotyping test with standard treatment. The Spartan RX CYP2C19 genetic device was initially tested in healthy volunteers before the study began. Twenty three individuals in either the tested or the standard treatment group carried at least one CYP2C19*2 allele. None of the genotyped carriers reached the 234 PRU cut-off value (set by the authors) at day 7 , compared with $30 \%$ of patients on standard treatment which obtained those high PRU values. The point-of-care genetic test has very high sensitivity and specificity and can be performed by the bedside. Moreover, 
this trial is also the first randomised investigation of selective use of prasugrel in CYP2C19*2 carriers after PCI, showing that this drug can reduce HTPR as opposed to clopidogrel. It can indicate that genetic factors do not influence the effectiveness of this new generation ADP-receptor antagonist [23].

ADP-receptor antagonists like prasugrel provide a more rapid, potent and less variable P2Y12-receptor inhibition. However, the increased risk of major bleeding with the novel P2Y12-receptor antagonists cannot be missed [13]. Mega et al. performed a large study of patients with genetic polymorphisms and their response to prasugrel. They examined the association of the genetic variants; CYP2C19, CYP2C9, CYP2B6, CYP3A5, CYP1A2 with cardiovascular outcomes in ACS patients. No significant association between the tested alleles and cardiovascular events was found, among healthy individuals or the sick. The data implies that the CYP2C19*2 allele has a significant impact on clopidogrel activity, as genetic variants do not affect outcomes in patients treated with prasugrel. Among prasugrel-treated people, carriers did not have a decreased platelet inhibition level compared with non-carriers [20].

A study performed by Charlotte Grosdidier et al. genotyped 730 patients taking either clopidogrel or prasugrel. One month after a procedure, PR was measured by the VASP method. Data revealed that prasugrel inhibited platelets better than clopidorgel, despite the genotype. Results showed that more patients taking prasugrel had low on-treatment platelet reactivity and this fact was also associated with an elevated bleeding risk [24].

The last publication that we quote in our article tried to answer the question why studies of tailored anti-platelet therapy failed so far [25]. Despite reducing platelet reactivity, platelet function monitoring did not reduce the incidence of cardiac ischaemic events. The authors discussed several important trials like ARCTIC, GRAVITAS and TRIGGER-PCI, which might partly have led to negative results. For instance, high-risk patients were excluded and randomization was performed a few hours after PCI. Markedly more patients with HTPR were switched to a higher dose of clopidogrel instead of prasugrel and the primary endpoints were too general. Also, use of a broad definition of myocardial injury might be inappropriate and consequently explains the results. A much larger sample size during studies with novel platelet inhibitors should be tested to show statistical differences. HTPR seems to be crucial in the early phase of PCI; therefore, the test timing and drug or dose switch should be done before or at the beginning of procedure. Until now it is recommended to test only patients undergoing high-risk PCI or with a history of stent $[25,26]$.

The topic of platelet function is attracting more and more attention from cardiology experts. The recommendation for platelet function tests may become stronger in the upcoming European Society of Cardiology (ESC) guidelines; this is partly supported by the recent expert position paper from the European Heart Journal [5].

According to ESC guidelines on non-ST segment elevation acute coronary syndromes and on ST-segment elevation myocardial infarction, prasugrel and tricagrelor are recommended for patients without contraindications, while clopidogrel should be administered if these drugs are not available. However, the American College of Cardiology Foundation (ACCE), the American Heart Association (AHA) and the Society for Cardiovascular Angiography and Intervention (SCAI) recommendations do not prefer novel inhibitors over clopidogrel, as clinical data is still inconclusive. Platelet function testing received a class IIb indication according to 2011 ESC guidelines. Aggregometry has not shown clinical benefit and is not indicated to be used routinely. ACCE, AHA and SCAI 2011 guidelines consider function testing among patients subjected to poor clinical outcome. Testing of PR for aspirin-dose adjustment is not recommended [5].

\section{Conclusions}

In our manuscript we try to summarize the most recent evidence behind aggregometry and genotyping of patients on anti-platelet treatment. In our analysis of studies, 5 trials and 1 meta-analysis are in favour of assessment of platelet reactivity with aggregometry methods, while one is not. As for genotyping, 10 studies show a positive clinical effect on patient outcome, while one does not support the use of this method in medical practice. The effective use of clopidogrel may involve genotyping or pharmacodynamics monitoring, while the use of prasugrel avoids this problem, although it carries a higher risk of bleeding [20].

Genotype is an unchangeable factor that affects platelet activity. An advantage of genotyping is that the patient does not have to be on a specific treatment while tested. The best method of identifying high-risk individuals could be both genotyping and platelet-function testing (phenotype). The findings indicate that personalisation of antiplatelet therapy might decrease adverse ischaemic outcomes [27].

As we can see, an objective conclusion from the clinical trials cannot be drawn and the results vary. 
Moreover, data concerning the advantages of genotyping patients is still unclear. However, more studies show benefits of adjusted treatment based on PR testing by aggregometry methods or genotyping.
Undoubtedly, the problem of ischaemic and bleeding events after PCI are in line with administered therapy, which could be tailored individually on the basis of genotype and platelet reactivity.

\section{References}

[1] Campo G, Parrinello G, Ferraresi P, Lunghi B, Tebaldi M, Miccoli M, Marchesini J, Bernardi F, Ferrari R, Valgimigli M: Prospective evaluation of on-clopidogrel platelet reactivity over time in patients treated with percutaneous coronary intervention relationship with gene polymorphisms and clinical outcome. J Am Coll Cardiol 2011, 57, 2474-2483.

[2] Savi P, Pereillo JM, Uzabiaga MF, Combalbert J, Picard C, Maffrand JP, Pascal M, Herbert JM: Identification and biological activity of the active metabolite of clopidogrel. Thromb Haemost 2000, 84, 891-896.

[3] Pereillo JM, Maftouh M, Andrieu A, Uzabiaga MF, Fedeli O, Savi P, Pascal M, Herbert JM, Maffrand JP, Picard C: Structure and stereochemistry of the active metabolite of clopidogrel. Drug Metab Dispos 2002, 30, 1288-1295.

[4] Gurbel PA, Tantry US: Clopidogrel resistance? Thromb Res 2007, 120, 311-321.

[5] Aradi D, Storey RF, Komocsi A, Trenk D, Dietrich G, Kiss RG, Husted S, Bonello L, Sibbing D, Collet J, Huber K: Expert poision paper on the role of platelet function testing in patients undergoing percutaneous coronary intervention. Eur Heart J 2014, 35, 209-215.

[6] Hulot JS, Bura A, Villard E, Azizi M, Remones V, Goyenvalle C, Aiach M, Lechat P, Gaussem P: Cytochrome P450 2C19 loss-of-function polymorphism is a major determinant of clopidogrel responsiveness in healthy subjects. Blood 2006, 108, 2244-2247.

[7] Siller-Matula JM, Lang I, Christ G, Jilma B: Calcium-channel blockers reduce the antiplatelet effect of clopidogrel. J Am Coll Cardiol 2008, 52, 1557-1563.

[8] Varenhorst C, James S, Erlinge D, Braun OO, Brandt JT, Winters KJ, Jakubowski JA, Olofsson S, Wallentin L, Siegbahn A: Assessment of P2Y(12) inhibition with the point-of-care device VerifyNow P2Y12 in patients treated with prasugrelor clopidogrel coadministered with aspirin. Am Heart J 2009, 157, 562.e1-9.

[9] Freynhofer MK, Brozovic I, Bruno V, Farhan S, Vogt W, Schomig A, Kastrati A, von Beckerath N: Multiple electrode aggregometry and vasodilator stimulated phosphoprotein-phosphorylation assay in clinical routine for prediction of postprocedural major adverse cardiovascular events. Thromb Heamost 2011, 106, 230-239.

[10] Sibbing D, Braun S, Morath T, Mehilii J, Vogt W, Schomig A, Kastrati A, von Veckerath N: Platelet reactivity after clopidogrel treatment assessed with point-of-care analysis and early-eluting stent thrombosis. J Am Coll Cardiol 2009, 53, 849-856.

[11] Jeong YH, Bliden KP, Antonino MJ, Park KS, Tantry US, Gurbel PA: Usefulness of the VerifyNow P2Y12 assay to evaluate the antiplatelet effects of ticagrelor and clopidogreltherapies. Am Heart J 2012, 164, 35-42.

[12] Sambu N, Radhakrishnan A, Dent H, Calver AL, Corbett S, Gray H, Simpson IA, Curzen N: Personalised antiplatelet therapy in stent thrombosis: observations from the Clopidogrel Resistance in StentThrombosis (CREST) registry. Heart 2012, 98, 706-711.

[13] Bonello L, Laine M, Baumstarck K, Fernandez J, Maillard L, Peyrol M, Bessereau J, Aradi D, Camilleri E, Roubille F, Piot C, Paganelli F, Camoin-Jau L, Dignat-George F: A randomized trial of platelet reactivity monitoring-adjusted clopidogrel therapy vs. prasugrel therapy to reduce high on-treatment platelet reactivity. Int J Cardiol 2013, 168, 4244-4248.

[14] Price MJ, Angiolillo DJ, Teirstein PS, Lillie E, Manoukian SV, Berger PB, Tanguay JF, Cannon CP, Topol EJ: Platelet reactivity and cardiovascular outcomes after percutaneous coronary intervention: a time-dependentanalysis of the Gauging Responsiveness with a VerifyNow P2Y12 assay: Impact on Thrombosis and Safety (GRAVITAS) trial. Circulation 2011, 124, 1132-1137.

[15] Aradi D, Komócsi A, Price MJ, Cuisset T, Ari H, Hazarbasanov D, Trenk D, Sibbing D, Valgimigli M, Bonello L: Efficacy and safety of intensified antiplatelet therapy on the basis of platelet reactivity testing in patients afterpercutaneous coronary intervention: systematic review and meta-analysis. Int J Cardiol 2013, 167, 2140-2148.

[16] Collet JP, Cuisset T, Rangé G, Cayla G, Elhadad S, Pouillot C, Henry P, Motreff P, Carrié D, Boueri Z, Belle L, Van Belle E, Rousseau H, Aubry P, Monségu J, Sabouret P, O’Connor SA, Abtan J, Kerneis M, Saint-Etienne C, Barthélémy O, Beygui F, Silvain J, Vicaut E, Montalescot G: Bedside monitoring to adjust antiplatelet therapy for coronary stenting. N Engl J Med 2012, 367, 2100-2109.

[17] Rehmel JL, Eckstein JA, Farid NA, Heim JB, Kasper SC, Kurihara A, Wrighton SA, Ring BJ: Interactions of two major metabolites of prasugrel, a thienopyridine antiplatelet agent, with the cytochromes P450. Drug Metab Dispos 2006, 34, 600-607.

[18] Hulot JS, Collet JP, Silvain J, Pena A, Bellemain-Appaix A, Barthélémy O, Cayla G, Beygui F, Montalescot G: Cardiovascular risk in clopidogrel treated patients according to cyrochrome $\mathrm{P} 450$ 2C19² loss-of-function allele or proton pump inhibitor coadministration: a systematic meta-analysis. J Am Coll Cardiol 2010, 56, 134-143.

[19] Harmsze A, van Werkum JW, Bouman HJ, Ruven HJ, Breet NJ, Ten Berg JM, Hackeng CM, Tjoeng MM, Klungel $\mathrm{OH}$, de Boer A, Deneer VH: Besides CYP2C19*2, the variant allele CYP2C9*3 is associated with higher onclopidogrel platelet reactivity inpatients on dual antiplatelet therapy undergoing elective coronary stent implantation. Pharmacogenet Genomics 2010, 20, 18-25. 
[20] Mega JL, Close SL, Wiviott SD, Shen L, Hockett RD, Brandt JT, Walker JR, Antman EM, Macias W, Braunwald E, Sabatine MS: Cytochrome p-450 polymorphisms and response to clopidogrel. N Engl J Med 2009, 360, 354-362.

[21] Simon T, Verstuyft C, Mary-Krause M, Quteineh L, Drouet E, Méneveau N, Steg PG, Ferrières J, Danchin N, Becquemont L: Genetic Determinants of Response to Clopidogrel and Cardiovascular Events. N Engl J Med 2009, 360, 363-375.

[22] Mega JL, Hochholzer W, Frelinger AL, Kluk MJ, Angiolillo DJ, Kereiakes DJ, Isserman S, Rogers WJ, Ruff CT, Contant C, Pencina MJ, Scirica BM, Longtine JA, Michelson AD, Sabatine MS: Dosing clopidogrel based on CYP2C19 genotype and the effect on platelet reactivity in patients with stablecardiovascular disease. JAMA 2011, 306, 2221-2228.

[23] Roberts JD, Wells GA, Le May MR, Labinaz M, Glover C, Froeschl M, Dick A, Marguis JF, O’Brien E, Goncalves S, Druce I, Stewart A, Gollob MH, So DY: Point-of-care genetic testing for personalisation of antiplatelet treatment (RAPID GENE): a prospective, randomised, proof-of-concept trial. Lancet 2012, 379, 1705-1711.

[24] Grosdidier C, Quilici J, Loosveld M, Camoin L, Moro PJ, Saut N, Gaborit B, Pankert M, Cohen W, Lambert M, Beguin S, Morange PE, Bonnet JL, Alessi MC, Cuisset T: Effect of CYP2C19^ 2 and ${ }^{\star} 17$ genetic variants on platelet response to clopidogrel and prasugrel maintenance doseand relation to bleeding complications. Am J Cardiol 2013, 111, 985-990.

[25] Siller-Matula JM, Jilma B: Why have studies of tailored antiplatelet therapy failed so far? Thromb Haemost 2013, 110, 628-631.

[26] Bonello L, Tantry US, Marcucci R, Blindt R, Angiolillo DJ, Becker R, Bhatt DL, Cattaneo M, Collet JP, Cuisset T, Gachet C, Montalescot G, Jennings LK, Kereiakes D, Sibbing D, Trenk D, Van Werkum JW, Paganelli F, Price MJ, Waksman R, Gurbel PA: Consensus and future directions on the definition of high on-treatment platelet reactivity to adenosine diphosphate. Am J Cardiol 2010, 56, 919-933.

[27] Roberts JD, Wells GA, Le May MR, Labinaz M, Glover C, Froeschl M, Dick A, Marguis JF, O’Brien E, Goncalves S, Druce I, Stewart A, Gollob MH, So DY: Point-of-care genetic testing for personalisation of antiplatelet treatment (RAPID GENE): a prospective,randomised, proof-of-concept trial. Lancet 2012, 379, 1705-1711.

\section{Address for correspondence:}

Sylwia N. Gajda

$1^{\text {st }}$ Department of Cardiology

Public Central Teaching Hospital

Słoneczne 8/44

97-400 Bełchatów

Poland

E-mail: cornysylwianatalia@gmail.com

Conflict of interest: None declared

Received: 3.04 .2014

Revised: 6.05.2014

Accepted: 18.06.2014 